\title{
RESENHAS
}

CHARLE, Christophe. 2008. Théatre en Capitales : naissance de la Societe du Spectacle. Paris, Berlin, Londres et Vienne (1860-1914). Paris : A. Michel.

\section{EM BUSCA DE UMA SOCIEDADE DO ESPETÁCULO PERDIDA: DESAFIOS DA HISTÓRIA SOCIAL DOTEATRO EUROPEU}

\author{
Rafael Faraco Benthien
}

Christophe Charle é atualmente professor de história contemporânea na Sorbonne (Paris I), estando também ligado a vários projetos coletivos de pesquisa dentro e fora da França. Desde o início de sua carreira como pesquisador, na década de 1970, ele vem se destacando por seus estudos sobre a composição e as transformações das elites nacionais européias entre fins do século XIX e primórdios do XX. Em alguns desses trabalhos, analisou as trajetórias e a produção específica de professores universitários, jornalistas, artistas e altos funcionários de seu próprio país (CHARLE, 1979; 1980; 1990; 2004). Em outros, tratou das mesmas categorias profissionais a partir de uma perspectiva mais ampla, comparando ora a política, ora a arte, ora o sistema de ensino de vários Estados europeus (CHARLE, 1996; 2001). Independentemente da escala, mas privilegiando sempre a interface entre História e Sociologia, Charle empenhou-se em mostrar os conflitos e as tensões inerentes à complexificação da divisão do trabalho de dominação social na modernidade.

Théâtre en capitales: naissance de la société du spectacle leva adiante o mesmo horizonte de temas, embora o faça com uma quantidade de fontes e com um leque comparativo antes jamais mobilizados pelo pesquisador. Isso se explica porque, diferente do que uma leitura apressada do título pode sugerir, o livro não propõe apenas uma história dos teatros de quatro importantes capitais européias, entre os anos 1860 e 1914 . O autor realiza, antes, uma história social dessas cidades e de seus habitantes a partir do teatro.

Similar inversão de papéis nada tem de ingênua ou de gratuita. Com efeito, enquanto produção artística, também essa modalidade de espetáculo permite a discussão de inúmeros aspectos da vida econômica, política e cultural dos grupos envolvidos direta e indiretamente com ela. Tal recorte temático é ainda mais analiticamente estratégico se levarmos em conta o aumento do número absoluto e a progressiva diversificação de tais grupos no período tratado, sobretudo em função da crescente democratização do acesso ao teatro. Daí o autor propor-se a falar de uma "sociedade do espetáculo" ou, em outras palavras, de uma sociedade cujo epicentro pode ser apenas vislumbrado desse espaço.

A centralidade social do teatro explica, a reboque, a escolha das cidades estudadas (Paris, Londres, Viena e Berlim), muito embora outras sejam evocadas en passant (Munique, Nápoles, Nova Iorque, Rio de Janeiro). É aí, sustenta o autor, que o acesso aos espetáculos amplia-se de maneira inédita, deixando traços documentais nada desprezíveis (estatísticas governamentais, registros das próprias salas de teatro, críticas das peças na imprensa). Some-se a isso a consolidação de um circuito internacional também sem precedentes de peças, de artistas e dos públicos das referidas capitais, tendo Paris como maior núcleo exportador. Graças a um tal contexto e partindo da constatação dos sucessos e fracassos de certos temas, Charle permite-se isolar variáveis capazes de explicar algo dessas acolhidas particulares, dos tabus que elas anunciam e das vidas a elas ligadas.

Outro ponto instigante do livro é que, ao tornar a história do teatro porta de entrada para alcançar-se a sociedade, ele permite explicitar e combater certos a priori alimentados por uma história da arte mais tradicionalista. Isso ocorre porque, por um lado, o livro escapa à tentação de reduzir o teatro às suas formas, evitando assim uma leitura puramente internalista. Não que o enredo das peças e sua cenografia, bem como o gestual e as vestimentas dos atores sejam desinteressantes. O ponto central, no entanto, é a discussão dessas variáveis sempre em relação a variáveis de outras ordens (as trajetórias e a competição dos agentes engajados na produção e no consumo dos produtos teatrais). Por outro lado, também não interessa a Charle reduzir o teatro a uma expressão qualquer de um certo contexto social ou cultural, como se costuma proceder entre certos 
herdeiros da tradição marxista e no âmbito dos cultural studies. Não por acaso, o mundo do teatro apresentado no livro está longe da suscitar a visão encantada de uma comunidade unida em torno de ideais universalmente partilhados, tampouco traduz uma reedição automática da luta de classes. Trata-se, sim, de um espaço de concorrência, de estratégias de diferenciação sociais compreensíveis a partir de padrões de relações muito específicos. Como se verá a seguir, o autor está longe de esgotar todas as variáveis internas e externas que compõe o universo do teatro. A vantagem é que há aqui um convite para cruzar essas diferentes dimensões, sem necessariamente partir da determinação de uma sobre outra.

Para realizar tal pesquisa, Charle divide o livro em duas grandes partes, realizando nelas investigações de escopo e propósito diferentes. A primeira parte, intitulada "Les Sociétés du spectacle" e subdividida em cinco capítulos, trata de aspectos morfológicos mais gerais das sociedades estudadas. Vê-se, nesse primeiro momento, o autor privilegiar uma análise quantitativa. Em "Le Siècle des théâtres”, o primeiro desses capítulos, Charle discute a expansão da oferta teatral nas capitais. Concorrem aí, para auxiliar a análise, uma história social da expansão urbana, mas também estudos sobre os efeitos da liberalização econômica característica do período. Interessa ao autor entender por que, por exemplo, em Londres, Paris e Viena novas salas não foram abertas seguindo a mesma direção da urbanização, o que ocorreu já em Berlim. Para explicar isso, o livro vale-se de estatísticas relativas às recomposições populacionais dos bairros, à evolução do preço dos ingressos, à concorrência de outras modalidades de diversão (os cabarés e cafés em bairros mais populares), à ampliação da rede de transportes urbanos (criando a possibilidade de centros teatrais não totalmente dependentes do público local) e ao controle e/ou censura das autoridades governamentais (particularmente atuantes na Inglaterra e nos impérios de língua alemã).

Nos próximos três capítulos da obra, Charle aborda as pontas do triângulo diretamente associado ao teatro, quais sejam: os diretores, os atores e os autores. O interesse aqui é mostrar como essas três categorias profissionais estão longe de serem tão homogênas como o simples ato de sua nomeação parece supor. Para tanto, a seqüência da argumentação é, em geral, a mesma. De início, discute-se o estado das fontes existentes nas quatro capitais, bem como as idéias pré-concebidas associadas pela historiografia a cada uma das categorias sociais investigadas. Em seguida, realiza-se um levantamento dos dados relativos às origens sociais dos membros dos três grupos, bem como os informes sobre suas formações escolares e/ou profissionalizantes e eventuais reconversões de capitais (seja no sentido da transferência de um capital externo ao mundo artístico para seu interior, seja na direção da transferência de uma modalidade de reconhecimento interno ao campo à outra - como, por exemplo, a do ator que utiliza seu sucesso no palco para alavancar projetos de direção ou de autoria). Por fim, todos esses dados são reunidos na forma de uma biografia comparada, a partir da qual são problematizados os pontos comuns e as divergências das quatro cidades no tocante à competição interna de cada classe profissional, bem como quanto às suas relações com as demais.

O quinto capítulo, “À La Recherche du succès”, funciona como uma espécie de conclusão da primeira parte. Nele, o autor procura entender como diretores, atores e autores engajaram-se na sedução de um grupo bastante heterogêneo de profanos, o público. Compreender as regras do sucesso, no entando, requer um conhecimento das diversas demandas então presentes. Já quando discutiu o culto a certos atores nos capítulos anteriores, Charle estabelece uma divisão que retorna aqui com força: a separação entre boulevard literário, médio e popular. Segundo ele, todas as capitais estudadas construíram espaços que poderiam ser assim nomeados. O gosto do público, em geral associado a outros dispositivos aparentemente tão banais quanto o preço dos ingressos e o número de cadeiras das salas, atuava como um fator decisivo de exclusão social e era levado em conta com maior ou menor maestria por todos os indivíduos implicados na sociedade do espetáculo. Assim, por exemplo, uma tragédia clássica, gênero considerado nobre e acessível a um número limitado de espectadores, só poderia gerar um lucro financeiro e obter sucesso de crítica preenchidas certas condições (a correta escolha do teatro, dos atores, do escritor e do diretor). Pela mesma lógica, peças ligadas a gêneros mixtos e ligeiros abordando assuntos da moda poderiam ser encontradas em um número maior de salas, persistindo na programação por um tempo maior. Saber exatamente qual é a aceitação de cada gênero, como funciona a escala de valores estéticos associados a eles, bem como os lugares que se prestam a encená-los permite observar em funcionamento as discriminações sociais de toda uma época. Vê-se, novamente, o autor partir do teatro para pensar algo além dele.

A segunda parte do livro, "Sociétés en représentation(s)", interage com todo o já dito por meio de análises mais verticais, qualitativas. Com efeito, Charle admite os limites hermenêuticos das análises quantitativas, as quais permitem capturar apenas em linhas gerais os conflitos característicos do período. É preciso, portanto, 
fazer intervir dados de outras naturezas (diários, cartas, críticas de jornal, entre outros) quando se quer lançar uma outra luz sobre as questões já tratadas.

Nesse sentido, o sexto capítulo, “Publics de Londres et Paris”, busca destruir o mito de que Londres caracterizava-se, durante o século XIX, por um teatro de entretenimento, enquanto Paris cultivaria mais sua dimensão estética. A partir de um estudo da toponímia dos teatros, dos tipos de peças encenadas e do público que freqüenta as salas londrinas, Charle mostra como há uma convergência cada vez maior entre a evolução do teatro lá e em Paris. Assim, nos dois locais, ele sublinha a consolidação de uma área urbana especializada na produção teatral, a qual, apesar de dominada pela grande burguesia da cidade, presta-se com alguma freqüência às (con)fusões de estratos sociais locais e internacionais (o West-End, em Londres; o Centro-Norte, em Paris). Além disso, nas duas capitais desenvolvem-se espaços alternativos de teatros fora desse eixo central, nos quais são representadas peças ao gosto de todos os boulevards existentes (aqueles relativos às elites letradas e/ou endinheiradas de localidades “marginais”, ou às camadas menos favorecidas da população).

O sétimo capítulo, “Paris capitale théâtrale de l'Europe?”, explora o curioso tópico da exportaçãoimportação de produtos culturais. Paris, nessa direção, atua como espaço privilegiado de exportação, seja em função do glamour que se criou em torno de sua produção (gerando demandas de várias outras elites nacionais), seja em função do número de pessoas lá envolvidas com o teatro (quantidade suficiente para tornar econômica e simbolicamente rentável a ida para fora do país). Quanto a esse ponto, por um lado, Charle aponta para a pioneira liberalização do teatro francês, permitindo um rápido aumento da oferta local. Um tal aparato, cada vez mais complexo e competitivo, facilitava o desenvolvimento de um turismo do espetáculo, assim como estimulava os artistas a irem buscar mercados nos quais eles não estivessem submetidos às leis de oferta ordinárias. Muitas montagens caras ou malsucedidas tinham assim de ir a outras capitais buscando recuperar ou maximizar lucros financeiros. O mesmo pode ser dito de atores e atrizes desconhecidos ou esquecidos, os quais buscavam ganhar ou recuperar seu carisma cativando públicos fora de seus lugares de origem. Por outro lado, o mesmo processo de exportação é utilizado também para mapear o que está em questão para quem recebe o espetáculo. Tal exercício permite, por exemplo, explorar a cisão das elites imperiais (a partir das diferenças de recepção das peças francesas em capitais nacionais no interior do Império Austro-Húngaro). Em todos os casos, porém, tal predominância do teatro parisiense permite pensar a existência de uma linguagem teatral internacional, com a qual e contra a qual as tradições locais reagem (o que gera também, por certo, algum efeito no próprio centro nevrálgico da sociedade do espetáculo).

O capítulo seguinte, “La Société en réprésentations”, utiliza-se do expediente da leitura interna das peças para enriquecer os dados apresentados na primeira parte do livro. Charle interessa-se em realizar aqui um inventário das figuras sociais representadas no espaço cênico, bem como em isolar os símbolos que as caracterizam. É preciso enfatizar, porém, que não se trata de uma simples leitura interna das peças, pois o autor toma o cuidado de não confundir o real e sua representação, tampouco isola o mundo representado como se ele possuísse um estatuto ontológico próprio. Há, assim, logo na seqüência do capítulo, um interessante inventário dos tipos de personagens, em termos de categorias sociais, presentes em várias obras de escritores consagrados no período. Em seguida, cada uma delas é tratada em particular (nobres, burgueses, mulheres, operários e patrões). A conclusão mais geral do autor sugere que, a despeito das críticas das vanguardas teatrais sobre a irrealidade desse mundo representado (ou seja, seu conservadorismo social e moral), há, sim, uma contínua tendência à inovação no teatro burguês do século XIX. Esse teatro reage às intensas transformações do período, assimilando, mesmo que por meio de chavões e eufemismos, as novas figuras e os novos problemas sociais nas capitais investigadas.

O nono capítulo, “Coups de Théâtre: théâtre, morale et politique”, evoca os conflitos políticos do período a partir do teatro. Por um lado, o tema tratado é o da luta dos diversos envolvidos no mundo do espetáculo pela flexibilização das agendas de censura. Por outro, o que interessa ao autor é a utilização do espaço físico do teatro e de seus arredores como lugares de manifestação pública (vaias a autoridades presentes na sala, protestos em áreas públicas contra artistas ou temas considerados moralemente nocivos). Vários episódios da vida teatral das cidades enriquecem aqui a narrativa do livro. Discute-se, entre outros casos, as lutas da vanguardas inglesas para viabilizar o fim da censura, a dificuldade crescente que Schnitzler enfrenta no trato com as autoridades vienenses cada vez mais assustadas com demandas nacionalistas no interior do Império Austro-Húngaro, ou ainda as estratégias polemistas da Front National para obrigar o governo francês a barrar a atividade profissional de um escritor judeu. 
No epílogo que encerra a segunda parte do livro, Charle aborda o delicado tema das vanguardas teatrais (tema, no entanto, já trabalhado por ele no início de sua carreira). Passando em revista as bandeiras dos diversos grupos (sobretudo as do naturalismo e as do simbolismo), o autor discute as dificuldades inerentes à institucionalização e à consagração de suas propostas. Constata ele que, para além da versão encantada da história canônica das vanguardas, os circuitos assim identificados permaneceram muito restritos e suas propostas não se consolidaram enquanto alternativas para o sistema de entretenimento maior. Faltou público, espaço e dinheiro, assim como capacidade de acumular experiências a partir dos fracassos anteriores. Diante dessas condições difíceis, restava aos artistas apostar no circuito internacional (o que, no entanto, garantia apenas uma sobrevida), ou ainda aceitar negociar com o sistema vigente (como Zola fez com a adaptação de alguns de seus romances). Por certo, isso não significa que a estética teatral tenha ficado indiferente à atividade vanguardista. Mas aceitar tal influência não significa aceitar que todo o conjunto das clivagens sociais e simbólicas operacionalizadas no e pelo teatro tenha sido colocado em cheque por ela.

A conclusão do livro, “D’une société du spectacle à l'autre”, retoma essas discussões do epílogo por um outro viés. Aqui, porém, interessa ao autor marcar como a sociedade do espetáculo teatral, conforme constituiu-se na Europa da segunda metade do século XIX, foi colocada em xeque por uma outra: a sociedade do cinema americano. Rapidamente, o autor sugere que a concorrência entre as duas atividades foi ganha pelo cinema, mas que isso não significou mudanças estruturais nas formas de reprodução das diferenças sociais. Também no mundo do cinema existem as vanguardas, os atores, os diretores e os produtores, bem como os publicos segmentados. Se o jogo está longe de ser o mesmo, tampouco trata-se de um Outro absoluto.

Uma vez finda a apresentação do autor e do trabalho, resta discutir sua pertinência científica. Antes de mais nada, cabe aqui afirmar que, do ponto de vista da história social, o trabalho é de indiscutível qualidade. Isso se deve, sobretudo, às enormes dificuldades analíticas oriundas da própria ambição do livro. São muitas fontes diferentes, muitos contextos particulares, tudo exigindo uma delicada costura. Na trama narrativa, nem sempre fácil de ser acompanhada, tal complexidade produz algo como um efeito "bumerangue”, obrigando o leitor a voltar constantemente às informações já discutidas. Assim, por exemplo, compreende-se melhor a expansão do mercado teatral em Paris após estudar os casos particulares de Londres, Berlim e Viena. E o autor, atento a isso, insere retornos na própria seqüência do texto, promovendo ativamente a comparação. Em suma, ele evita a simples exposição de casos particulares sucessivos, realizando um esforço de síntese. Há, portanto, muito o que se aprender com a obra, assim como muito o que se discutir a partir dela.

Cabe ainda apontar que Charle insere-se em uma rica e recente vertente de estudos de história social da arte. Tal vertente, longe de representar uma ruptura radical com o que se fez no passado, incorpora métodos e questões, buscando pesar a intensa acumulação de refexão já existente sobre o tema. Na esteira de Pierre Bourdieu, é na superação de uma falsa dicotomia entre texto e contexto, da qual são reféns tanto leituras internalistas quanto explicações externalistas da arte, que o autor procede (cf. BOURDIEU, 1997, p. 53-89). Isso implica dizer que a intenção do autor não é dar conta de explicar toda a realidade, como um objetivista ingênuo, muito menos fazer um elogio de uma suposta subjetividade artística. Trata-se de isolar variáveis explicativas em uma complexa série documental, investiganda-a a partir de certas questões. Ora, o teatro abre imensas portas para se pensar toda um universo situado além das peças, dos agentes engajados diretamente em sua produção e de seu público. O teatro é - como a pintura, a música e a literatura podem ser - uma porta de entrada para se pensar, por exemplo, a complexificação tanto da burocracia estatal (com suas estatísticas, serviços de censura e controle), como dos espaços urbanos e seus habitantes.

Vale propor ao leitor a leitura de outros trabalhos que podem ser identificados com essa mesma vertente. No campo dos estudos sobre o teatro, por exemplo, Anne Saada enfrentou, em um Doutorado orientado por Roger Chartier, questões parecidas quando tratou da recepção das peças de Diderot na Alemanha do século XVIII (SAADA, 2003). É interessante perceber como os mesmos padrões vistos por Charle no século XIX (a circulação das obras e os agentes envolvidos) aparecem já muito antes, embora em uma escala menor e com grupos mais restritos. Além do mais, tal livro de Charle permite o diálogo com uma obra como A pintura da vida moderna (CLARK, 2004), na qual se discute a Paris do mesmo período a partir de outros materiais (as pinturas dos Impressionistas) e priorizando uma série documental diferente (além dos próprios quadros, a crítica de arte jornalística e caricaturas da época). O mesmo pode ser ainda dito de Retrato e sociedade na arte italiana, embora nesse caso a aproximação se dê, sobretudo, em função dos procedimentos metodológicos similares defendidos nos dois casos (CASTELNUOVO, 2006). Isso vale, em particular, para a ambição do primeiro 
capítulo da mencionada obra, publicada originalmente em 1973. Nele, Castelnuovo propõe uma história da Itália moderna a partir dos retratos lá produzidos, discutindo os espaços de exposição dos retratos, bem como a relação entre encomandantes e artistas (cf. BENTHIEN, 2007).

Rafael Faraco Benthien (rfbenthien@hotmail.com) é Doutorando em História Social pela Universidade de São Paulo (USP) e bolsista da Fundação de Amparo à Pesquisa do Estado de São Paulo (Fapesp) e da Coordenação de Aperfeiçoamento de Pessoal de Nível Superior (Capes).

\section{REFERÊNCIASBIBLIOGRÁFICAS}

BENTHIEN, R. F. 2007. Resenha de "Retrato e sociedade na arte italiana. Ensaios de história social da arte". Revista de História, São Paulo, n. 156, p. 311-315. Disponível em : http://www.usp.br/revistadehistoria/ arquivos/RH-156.pdf. Acesso em : 17.maio.2009.

BOURDIEU, P. 1997. Razões práticas. Campinas : Papirus.

CASTELNUOVO, E. 2006. Retrato e sociedade na arte italiana. São Paulo : Companhia das Letras.

CLARK, T. 2004. A pintura da vida moderna. Paris na arte de Manet e de seus seguidores. São Paulo : Companhia das Letras.

CHARLE, C. 1979. La Crise littéraire à l'époque du naturalisme. Paris : ENS. 1980. Les Hauts fonctionnaires en France au XIXe siècle. Paris : Gallimard. . 1990. La Naissance des « intellectuels » (1880-1900). Paris : Minuit. 1996. Les Intellectuels en Europe au XIXe siècle. Essai d’histoire comparée. Paris : Seuil. .2001. La Crise des sociétés impériales. Essai d’histoire sociale comparée de l'Allemagne, de la France et de la Grande-Bretagne. Paris : Seuil.

2004. Le Siècle de la presse (1830-1939). Paris : Seuil.

SAADA, A. 2003. Inventer Diderot. Les constructions d'un auteur dans l'Allemagne des Lumières. Paris : CNRS. 